REGARDS

SUR L'ECONOMIE ALLEMANDE

BULLETIN ECONOMIQUE DU CIRAC
Regards sur l'économie allemande

Bulletin économique du CIRAC

$94 \mid 2009$

Varia

\title{
Théories économiques
}

ALCOUFFE Alain, DIEBOLT Claude (eds), La pensée économique allemande / GOLDSCHMIDT Nils, WOHLGEMUTH Michael (eds), Grundtexte zur Freiburger Tradition der Ordnungsökonomik

\section{(2) OpenEdition}

1 Journals

Édition électronique

URL : http://journals.openedition.org/rea/3984

DOI : $10.4000 /$ rea.3984

ISBN : 978-2-8218-0884-3

ISSN : 1965-0787

Éditeur

CIRAC

Édition imprimée

Date de publication : 1 décembre 2009

ISSN : 1156-8992

Référence électronique

"Théories économiques », Regards sur l'économie allemande [En ligne], 94 | décembre 2009, mis en ligne le 31 décembre 2009, consulté le 22 septembre 2020. URL : http://journals.openedition.org/rea/ 3984 ; DOl : https://doi.org/10.4000/rea.3984

Ce document a été généré automatiquement le 22 septembre 2020.

(c) CIRAC 


\section{Théories économiques}

ALCOUFFE Alain, DIEBOLT Claude (eds), La pensée économique

allemande / GOLDSCHMIDT Nils, WOHLGEMUTH Michael (eds), Grundtexte zur Freiburger Tradition der Ordnungsökonomik

\section{RÉFÉRENCE}

ALCOUFFE Alain, DIEBOLT Claude (eds), La pensée économique allemande - Préface

de Bertram Schefold, Economica, Paris, 2009, 462 p.

GOLDSCHMIDT Nils, WOHLGEMUTH Michael (eds), Grundtexte zur Freiburger

Tradition der Ordnungsökonomik, Coll. Untersuchungen zur Ordnungstheorie und

Ordnungspolitik du Walter Eucken Institut, vol. 50, Mohr Siebeck, Tübingen, 2008, 782

p.

1 A destination du grand public, mais aussi du monde scientifique, l'ouvrage d'ALCOUFFE/ DIEBOLT offre une lecture inter- voire transdisciplinaire de la pensée économique allemande des $\mathrm{XIX}^{\mathrm{e}}$ et $\mathrm{XX}^{\mathrm{e}}$ siècles, via l'intégration d'éléments historiques, philosophiques et sociologiques. A une première partie sur la pensée philosophique et le débat méthodologique succède une présentation des auteurs classiques et des théoriciens de l'économie sociale de marché, de Georg Wilhelm Friedrich Hegel à Walter Eucken. Quant à l'ouvrage dirigé par GOLDSCHMIDT/WOHLGEMUTH, il réunit les grands textes fondateurs de cette « Ecole de Fribourg » dont est issue la doctrine de l'économie sociale de marché. Ils présentent le large prisme des approches développées au fil du $\mathrm{XX}^{\mathrm{e}}$ siècle : la problématique du pouvoir des monopoles, la dialectique autorégulation par les acteurs économiques/réglementation par l'Etat, le concept "d'ordre » économique et social, la notion de concurrence... Les auteurs? Walter Eucken et Müller-Armack, bien sûr, mais aussi Otto Schlecht, Friedrich A. von Hayek, Wilhelm Röpke ou Ludwig Erhard... Leurs textes sont tous précédés d'une présentation de l'auteur et de son œuvre. Cet ouvrage, unique anthologie en son genre et de surcroît tiré sur un très beau papier couché, est à tous les égards une référence. (ib/sh) 